\title{
Blood lipids may have influence on the emotional well-being in young men
}

\author{
Edyta Kramek, Sylwia Jastrzebska, Renata Walczak-Jedrzejowska, Katarzyna Marchlewska, \\ Elzbieta Oszukowska, Anna Guminska, Krzysztof Kula, Jolanta Slowikowska-Hilczer*
}

Department of Andrology and Reproductive Endocrinology, Medical University of Lodz, Lodz, Poland;

*Corresponding Author: jolanta.slowikowska-hilczer@umed.lodz.pl

Received 14 January 2010; revised 4 February 2010; accepted 6 February 2010.

\begin{abstract}
Anamnestic data on general health and medical conditions were achieved from 136 men (20-49 yrs). Beck Depression Inventory II (BDI-II) questionnaire was used to assess depressive symptomatology. Body weight, height, waist and hip circumference, arterial blood pressure were measured. Serum levels of total cholesterol (TC), LDL cholesterol (LDL-C), HDL cholesterol (HDL-C), triglicerydes (TG), glucose, SHBG, total testosterone, DHEA-S and estradiol were determined. Calculated were body mass index (BMI), waist to hip ratio (WHR) and free testosterone index (FTI). In men aged 40-49 general health significantly got worse, BMI, WHR, blood pressure increased and mean serum levels of FTI, DHEA-S, estradiol decreased in comparison to younger men. Only in 40-49 age band BDI-II scoring was negatively related with $\mathrm{FTI}$, however, in the whole group there were no significant correlations. Nevertheless, some symptoms of depression were negatively related with LDL-C or HDL-C and positively with TG. Similar relations were found among young men, but not in the middle-aged. Conclusions: Only blood lipids may have influence on emotional well-being in young healthy men. The decreased testosterone level becomes probably the main risk factor for the lower mood in middle-aged men. Atherosclerosis risk factors and general health worsen with the advancing age, but they have no significant effect on psychological situation.
\end{abstract}

Keywords: Man; Depression; Sex Steroids; Lipids; General Health

\section{INTRODUCTION}

There are evidences of the relationship between hormo- nal changes in menstrual cycle and changes in mood in women $[1,2]$. Recent long-term, prospective studies have demonstrated that the transition to menopause is associated with higher risk for new onset and recurrent depression [3]. In men, however, interrelationship between the emotional state and sex steroids serum levels are controversial. Low testosterone serum level in hypogonadal men is characterised by depressed mood and emotional instability [4,5]. Androgen deficiency in the aging male, also referred to as late-onset hypogonadism (LOH), is a clinical and biochemical syndrome associated with advancing age and deficiency in serum testosterone levels below the young healthy adult male reference range [6]. It includes, among other symptoms, depressed mood, decreased vitality and low sex drive $[7,8]$. Several studies showed the significant improvement in the emotional well-being after testosterone [9-11] or dehydroepiandrosterone sulphate (DHEA-S) administration in hypogonadal men $[12,13]$. Nevertheless, physiologic studies were usually not successful in demonstrating a significantly negative relation of androgens with lower mood, especially in young men $[14,15]$.

Other evidences indicate that vascular disease may cause depression and thus cerebral atherosclerosis may be responsible for late-life depressed mood [16,17]. On the other side, several studies assessed the negative association between serum levels of total cholesterol or LDL-cholesterol and depressive symptoms, what denies the "vascular theory" $[18,19]$.

The aim of our study was to assess if emotional well-being in young men demonstrates a relationship with sex hormones or atherosclerosis risk factors in comparison to middle-aged men.

\section{METHODS}

\subsection{Subjects and Study Design}

The study was performed after the approval of the Bioethical Committee of the Medical University in Lodz, 
Poland. A group of 300 men was randomly recruited from the Lodz's city population register for participation in this study. The only criterion of the selection was age between 20-49 years. Subjects were invited by a letter to attend for a screening visit at the Department of Andrology and Reproductive Endocrinology. The overall response rate for participation was $46 \%$. Men who agreed to participate in the study (136 subjects, mean age $35.5 \pm$ 10 years) were divided into age bands: 20-29 (44 subjects), 30-39 (36 subjects) and 40-49 (56 subjects).

Subjects were asked to complete an interviewer- assisted questionnaire gathered information on sociodemographic, medical conditions and medications. General health was scored from 0 , when very good, to 3 , when very bad.

Although it is not possible to do it concisely, but we defined emotional well-being as the capacity to live a full and creative life, and the flexibility to deal with life's inevitable challenges. Overall it means the lack of depression symptoms [20]. To measure depressive symptomatology the Beck Depression Inventory II (BDI-II) questionnaire was used [21]. BDI-II contains 21 questions concerning: 1) sadness, 2) pessimism, 3) past failures, 4) loss of pleasure from things a man used to enjoy, 5) feelings of guilty, 6) feelings of punishment, 7) self-dislike, 8) self-criticism, 9) suicidal thoughts and wishes, 10) crying, 11) agitation, 12) loss of interest in other people or activities, 13) indecisiveness, 14) worthlessness, 15) loss of energy, 16) changes in sleeping pattern, 17) irritability, 18) changes in appetite, 19) concentration difficulty, 20) tiredness or fatigue, and 21) loss of interest in sex during past two weeks including a day of meeting. Each answer was scored on a scale value of 0 to 3. Cutoffs used: $0-13$-lack or minimal depression, 14-19-mild depression, 20-28-moderate depression, 29-63 - severe depression.

Body weight and height, waist and hip circumference and arterial blood pressure were measured using standard procedures. Calculated were body mass index (BMI $=$ weight $/$ height ${ }^{2}$ ) and waist to hip ratio (WHR).

\subsection{Hormone and Lipid Measurements}

Single venous blood samples were taken in the morning hours (8.00-10.00) in a fasting state, 12 hours after the last meal. Serum was separated and stored at $-80^{\circ} \mathrm{C}$ until assayed at the end of the study, not longer than 6 months.

Serum determinations of total testosterone, DHEA-S, estradiol and sex hormone binding globulin (SHBG) were performed. All hormones were measured using chemiluminescence immunoassay (Immulite 1000, DPC, USA). Detection limits were for: total testosterone- 0.5 $\mathrm{nmol} / \mathrm{L}$, DHEA-S $-3 \mu \mathrm{g} / \mathrm{dl}$, estradiol-20 $\mathrm{pmol} / \mathrm{L}$ and SHBG $-0.2 \mathrm{nmol} / \mathrm{L}$. Free testosterone index (FTI) was calculated as following: total testosterone/SHBG $\times 100$.
Serum levels of total cholesterol (TC, normal range: 3.0-5.2 $\mathrm{mmol} / \mathrm{L}$ ), LDL cholesterol (LDL-C, normal range: $<2.6 \mathrm{mmol} / \mathrm{L}$ ), HDL cholesterol (HDL-C, normal range: $>1.0 \mathrm{mmol} / \mathrm{L}$ ), triglicerydes $(\mathrm{TG}$, normal range: < $1.7 \mathrm{mmol} / \mathrm{L}$ ), and glucose (normal range: 3.3-5.5 mmol/L) were determined with the use of enzymatic methods (Cobas Integra 800, Roche Diagnostics, Poland).

\subsection{Statistical Analysis}

All statistical analyses were performed using Statistica for Windows PL software, version 8.0 (Statsoft, Cracow, Poland). Mean \pm standard deviation (SD) and median values have been used to express group data. Nonparametric analysis (Mann-Whitney U-test) was applied for comparison between groups after verification of values distribution (ANOVA). Correlations were examined using Spearman's linear regression analysis. $\mathrm{P}<0.05$ was considered significant.

\section{Results}

Table 1 presents self-reported health and physical status. General health significantly got worse in men aged 40-49 in comparison to younger ones. Significantly increased BMI, WHR, systolic and diastolic blood pressure were found also in this age band. One or more morbidities were reported by 16 men. The most frequent

Table 1. Results of physical and self-reported health characteristics.

\begin{tabular}{|c|c|c|c|}
\hline & \multicolumn{3}{|c|}{ Age band (years) } \\
\hline & $\begin{array}{l}20-29 \\
n=44\end{array}$ & $\begin{array}{l}30-39 \\
n=36\end{array}$ & $\begin{array}{l}40-49 \\
n=56\end{array}$ \\
\hline $\begin{array}{l}\text { General health } \\
\text { (score) }\end{array}$ & $1.1 \pm 1.5$ & $1.8 \pm 1.5$ & $2.0 \pm 1.3^{\mathrm{a}}$ \\
\hline BMI $\left(\mathrm{kg} / \mathrm{m}^{2}\right)$ & $24.7 \pm 3.6$ & $26.1 \pm 3.7^{\mathrm{c}}$ & $26.9 \pm 3.9^{\mathrm{a}}$ \\
\hline WHR & $0.88 \pm 0.1$ & $0.92 \pm 0.1$ & $0.96 \pm 0.1^{\mathrm{a}}$ \\
\hline Systolic BP & $131.5 \pm 12.8$ & $132.1 \pm 13.5$ & $142.9 \pm 20.4^{\mathrm{a}}$ \\
\hline Diastolic BP & $76.9 \pm 9.1$ & $78.0 \pm 9.6$ & $88.3 \pm 12.9^{a}$ \\
\hline \multicolumn{4}{|l|}{$\begin{array}{l}\text { Self-reported } \\
\text { morbidities: }\end{array}$} \\
\hline Hypertension & 1 & 1 & 4 \\
\hline Arrhythmia & 0 & 0 & 1 \\
\hline CAD & 0 & 0 & 1 \\
\hline GIU & 0 & 0 & 8 \\
\hline Neurosis & 0 & 0 & 1 \\
\hline Depression & 0 & 0 & 1 \\
\hline $\mathrm{BPH}$ & 0 & 0 & 1 \\
\hline
\end{tabular}

${ }^{\mathrm{a}} \mathrm{p}<0.001 ;{ }^{\mathrm{c}} \mathrm{p}<0.05$ vs. $20-29$ age band; Mann-Whitney U-test; $\mathrm{n}-$ number of subjects; BMI - body mass index; WHR - waist to hip ratio; $\mathrm{BP}$ - blood pressure; CAD - coronary artery disease; GIU - gastrointestinal ulcer; $\mathrm{BPH}$ - benign prostate hyperplasia 
were gastrointestinal ulcer (50\%) and hypertension $(37.5 \%)$. Nobody used antidepressants, psychotropic drugs, narcotics or lipid-lowering medications. None was denoted as alcoholic or drug addict.
Mean serum levels of DHEA-S, estradiol, as well as FTI, were significantly decreased, while SHBG increased, in men aged 40-49 in comparison to men aged 20-29 as shown in Table 2. In men 30-39 years old

Table 2. Results of hormonal determinations and serum levels of lipids in men between 20 and 49 years of age.

\begin{tabular}{|c|c|c|c|c|}
\hline & & \multicolumn{3}{|c|}{ Age band (years) } \\
\hline \multicolumn{2}{|c|}{ Hormones and lipids } & $\begin{array}{c}20-29 \\
\mathrm{n}=44\end{array}$ & \multirow{2}{*}{$\begin{array}{c}\begin{array}{c}30-39 \\
\mathrm{n}=36\end{array} \\
18.4 \pm 6.4\end{array}$} & \multirow{2}{*}{$\begin{array}{c}\begin{array}{c}40-49 \\
\mathrm{n}=56\end{array} \\
18.3 \pm 5.7\end{array}$} \\
\hline & $\mathrm{x} \pm \mathrm{SD}$ & $18.5 \pm 4.1$ & & \\
\hline $\begin{array}{c}\mathrm{TT} \\
(\mathrm{nmol} / \mathrm{L})\end{array}$ & median & 17.9 & 18.7 & 18.0 \\
\hline \multirow{4}{*}{ FTI } & range & $8.4-28.0$ & $7.5-34.6$ & $7.4-35.6$ \\
\hline & $\mathrm{x} \pm \mathrm{SD}$ & $84.5 \pm 30.4$ & $71.8 \pm 26.7^{\mathrm{c}}$ & $45.5 \pm 13.8^{\mathrm{a}}$ \\
\hline & median & 76.6 & 66.1 & 44.5 \\
\hline & range & $27.1-168.9$ & $31.9-160.2$ & $23.1-83.9$ \\
\hline \multirow{3}{*}{$\begin{array}{c}\text { DHEA-S } \\
(\mu \mathrm{g} / \mathrm{dl})\end{array}$} & $\mathrm{x} \pm \mathrm{SD}$ & $287.3 \pm 107.7$ & $259.0 \pm 102.3$ & $246.5 \pm 89.7^{\circ}$ \\
\hline & median & 251.5 & 233.0 & 229.5 \\
\hline & range & $107.0-572.0$ & $129.0-572.0$ & $88.4-456.9$ \\
\hline \multirow{3}{*}{$\begin{array}{l}\text { Estradiol } \\
(\mathrm{pmol} / \mathrm{L})\end{array}$} & $\mathrm{x} \pm \mathrm{SD}$ & $124.5 \pm 41.1$ & $100.3 \pm 36.9^{\mathrm{b}}$ & $90.0 \pm 26.1^{\mathrm{a}}$ \\
\hline & median & 117.3 & 93.5 & 87.6 \\
\hline & range & $45.5-208.8$ & $44.1-178.1$ & $45.3-164.4$ \\
\hline \multirow{3}{*}{$\begin{array}{c}\text { SHBG } \\
(\mathrm{nmol} / \mathrm{L})\end{array}$} & $\mathrm{x} \pm \mathrm{SD}$ & $24.0 \pm 8.4$ & $27.8 \pm 12.8$ & $43.3 \pm 19.4^{\mathrm{a}}$ \\
\hline & median & 22.7 & 25.4 & 39.4 \\
\hline & range & $8.9-49.9$ & $12.5-69.5$ & $15.4-106.0$ \\
\hline \multirow{3}{*}{$\begin{array}{c}\mathrm{TC} \\
(\mathrm{mmol} / \mathrm{L})\end{array}$} & $\mathrm{x} \pm \mathrm{SD}$ & $4.2 \pm 0.9$ & $4.8 \pm 1.0^{\mathrm{b}}$ & $6.1 \pm 0.9^{\mathrm{a}}$ \\
\hline & median & 4.1 & 4.6 & 6.2 \\
\hline & range & $2.6-7.5$ & $3.0-7.5$ & $3.8-7.5$ \\
\hline \multirow{3}{*}{$\begin{array}{c}\text { HDL-C } \\
(\mathrm{mmol} / \mathrm{L})\end{array}$} & $\mathrm{x} \pm \mathrm{SD}$ & $1.5 \pm 0.3$ & $1.5 \pm 0.4$ & $1.6 \pm 0.2^{\mathrm{c}}$ \\
\hline & median & 1.4 & 1.5 & 1.6 \\
\hline & range & $0.9-2.3$ & $0.9-2.4$ & $1.2-2.6$ \\
\hline \multirow{3}{*}{$\begin{array}{c}\text { LDL-C } \\
(\mathrm{mmol} / \mathrm{L})\end{array}$} & $\mathrm{x} \pm \mathrm{SD}$ & $2.2 \pm 0.8$ & $2.7 \pm 0.9^{c}$ & $3.5 \pm 1.2^{\mathrm{a}}$ \\
\hline & median & 2.2 & 2.5 & 3.3 \\
\hline & range & $1.0-5.0$ & $1.2-5.3$ & $1.2-6.1$ \\
\hline \multirow{3}{*}{$\begin{array}{c}\mathrm{TG} \\
(\mathrm{mmol} / \mathrm{L})\end{array}$} & $\mathrm{x} \pm \mathrm{SD}$ & $1.1 \pm 0.7$ & $1.5 \pm 1.2$ & $1.9 \pm 1.2^{\mathrm{a}}$ \\
\hline & median & 0.9 & 1.1 & 1.5 \\
\hline & range & $0.4-4.4$ & $0.3-5.7$ & $0.8-5.8$ \\
\hline
\end{tabular}

${ }^{\mathrm{a}} \mathrm{p}<0.001 ;{ }^{\mathrm{b}} \mathrm{p}<0.01 ;{ }^{\mathrm{c}} \mathrm{p}<0.05$ vs. $20-29$ age band, Mann-Whitney U-test; $\mathrm{n}$ - number of subjects, $\mathrm{x}$ - mean value, SD - standard deviation; TT - total testosterone; FTI - free testosterone index; DHEA-S - dehydroepiandrosterone sulphate; SHBG - sex hormone binding globuline; TC - total cholesterol; HDL-C - HDL cholesterol; LDL-C - LDL - cholesterol; TG - triglycerides 
significantly decreased were only FTI and estradiol. The mean serum levels of total testosterone did not differ significantly between the age groups.

Serum levels of all lipids were significantly increased in the oldest group of men in comparison to 20-29 age band. In those aged 30-39 significantly increased were TC and LDL-C. The level of glucose was within the normal range in all of the subjects.

It was recognised that 12 men $(8.8 \%)$ had mild depression (Table 3). One men from the youngest age band presented symptoms of severe depression. He had normal levels of all studied parameters (FTI-121.5). In 4 men aged 40-49 moderate depression was diagnosed, while in none of younger. All of them had low FTI (28.3-51.9) and increased TC (5.3-7.5 mmol/L). However, all of the subjects with more intensive depression reported adverse life events during last six months such as major financial problems, serious illness or injury to a close relatives, broken off a steady relationship and getting the sack from a job. These events might be reasons of lower mood.

Total scoring of BDI-II was not related with age, general health scoring, blood lipids and sex hormones serum levels. When correlations where performed for each age band separately it appeared that total scoring of BDI-II was negatively related with FTI, but only in 40-49 age band $(\mathrm{r}=-0.26, \mathrm{p}<0.05)$. Other correlations of total BDI-II where not found.

Among different symptoms of depression only difficulties in concentration were positively associated with the age $(r=0.18, p<0.05)$. Among hormones a negative association was observed between FTI and loss of interest in sex $(r=-0.21, p<0.05)$. More associations were found between lipids and symptoms of depression: negative between LDL-C and loss of energy $(r=-0.22, p<$ 0.01 ) or loss of pleasure from things a man used to enjoy $(\mathrm{r}=-0.2, \mathrm{p}<0.05)$, HDL-C and feelings of past failures $(\mathrm{r}=-0.31, \mathrm{p}<0.01)$ or suicidal thoughts or wishes $(\mathrm{r}=$ $-0.24, p<0.05)$. TG were positively correlated with feelings of past failures $(r=0.29, \mathrm{p}<0.01)$ and negatively with the self-assessment of general health $(\mathrm{r}=-0.18, \mathrm{p}<$ 0.05 ). Serum levels of TC were not associated with the

Table 3. Results of the Beck Depression Inventory II (BDI-II) in men 20-49 years old.

\begin{tabular}{|c|c|c|c|}
\hline \multirow{2}{*}{$\begin{array}{c}\text { Depression } \\
\text { intensity }\end{array}$} & \multicolumn{3}{|c|}{ Age band (years) } \\
\hline & $\begin{array}{c}20-29 \\
n=44(\%)\end{array}$ & $\begin{array}{c}30-39 \\
n=36(\%)\end{array}$ & $\begin{array}{c}40-49 \\
n=56(\%)\end{array}$ \\
\hline Lack or minimal & $40(90.9)$ & $31(86.1)$ & $48(85.8)$ \\
\hline Mild & $3(6.8)$ & $5(13.9)$ & $4(7.1)$ \\
\hline Moderate & 0 & 0 & $4(7.1)$ \\
\hline Severe & $1(2.3)$ & 0 & 0 \\
\hline
\end{tabular}

separate symptoms of depression. Similar relations were found among young men, but not in the middle-aged.

BMI, WHR and blood pressure were not correlated with the total scoring of BDI-II or single depression symptoms or the scoring of general health in the whole group, as well as in each age band.

\section{DISCUSSION}

Although total testosterone serum levels were unchanged with the age in our study, FTI, which is a counterpart of biologically active testosterone, decreased significantly. Moreover, DHEA-S and estradiol decreased with the advancing age, while the level of SHBG increased. Such phenomena were described in several studies [22-24]. There is a general consensus that serum levels of testosterone decline with age. This decline begins at about the $30^{\text {th }}$ year of life and decreases progressively as men get older. The European Male Aging Study (EMAS) provides one of the largest data sets to investigate hormonal variations in aging men. It revealed that total testosterone decreased by only $0.4 \% /$ year, whereas free testosterone decreased by $1.3 \% / y e a r$ [24]. Serum free testosterone concentrations decrease more than the total testosterone because of the increased levels of SHBG in older men. Since the circulating non-SHBG-bound testosterone (free and albumin-bound) is the biologically available form for activity at the target organs, measurements of this non-SHBG-bound testosterone better reflect the clinically important state of circulating testosterone than the total testosterone concentrations [25]. It is also known that serum concentrations of adrenal androgens such as dehydroepiandrosterone and its sulphate (DHEA and DHEA-S) and androstendione decrease with the increasing age [26,27]. The age trend of serum estrogen in men has been reported variously as declining [27,28] or steady [29].

Although significant decrease in serum levels of sex steroids were observed with the advancing age, in this study we have not found the direct relationship between emotional well-being and sex steroids in young men. Only in 40-49 age band total scoring of BDI-II was negatively related with FTI. It may indicate that after 40 testosterone serum level is so low that it may negatively influence the mood. Nevertheless, although most of the men with higher intensity of depression were above 40 , the most severe depression occurred in the 25 -year-old man, who had normal levels of sex steroids. The reason of lower mood was probably situational, because all of the depressed men reported recent adverse life events. The results of other studies on the influence of sex steroids on mood in men are controversial. In the Rancho Bernardo Study of 856 men aged 50-89, the BDI score was significantly and inversely associated with 
bioavailable testosterone, independent of age, weight change and physical activity [30]. Similar associations were seen for dihydrotestosterone, while estradiol was not associated with depressed mood. The Massachusetts Male Aging Study (MMAS) of 1709 men aged 40-70 revealed no correlation between the Center for Epidemiologic Studies Depression Scale (CES-D) and serum testosterone level [31]. Rubin et al. [15] showed that age was negatively correlated with baseline serum testosterone in patients with endogenous depression, but not in controls. Similar results, revealing that among men with major depression testosterone secretion may be reduced, were achieved by others [32,33]. However, signs and symptoms of major depression may overlap with apparent psychiatric sequel of hypogonadism. Woodman and Williams [34] found that $39 \%$ of hypogonadal men treated in an endocrinology clinic were also treated with medication for a psychiatric illnesses. These data suggest that some depressed older men may have state-dependent low testosterone levels and that some of them may improve with androgen treatment.

Among sex steroids only FTI was associated with the lost of interest in sex as the separate parameter of depression. There are a lot of studies showing the relationship between libido and androgens [7,35]. EMAS revealed that men with the lowest levels of total and free testosterone reported lower overall sexual function (OSF) scores in comparison to men with the highest testosterone levels [36]. There is also an improvement in the sexual function after treatment with testosterone [37].

We investigated also the state of general health because it may, as the only factor, lead to significant deterioration of mood. The oldest men worse estimated their health in comparison to younger and they reported more morbidities. They had more atherosclerosis risk factors: higher BMI, WHR, blood pressure and increased serum levels of TC, LDL-C and TG. In hypogonadal men, as well as in aging men, increase in total adipose tissue mass and the redistribution of fat from peripheral subcutaneous depots to central, intra-abdominal depots is well-documented [38-40]. Decreased testosterone level and visceral adipose tissue accumulation in the aging male probably represents the most important factor for premature morbidity and mortality from cardiovascular disease $[41,42]$. However, we did not find the impairment of mood with the advancing age or associations of total BDI-II scores with blood lipids, anthropometric results and the general health scoring. Nevertheless, there were relations between some symptoms of depression and blood lipids. LDL-C correlated negatively with the loss of energy and the loss of pleasure from things a man used to enjoy. It was found previously by other authors that low LDL-C level may predispose to acute depression and the risk of suicidal behaviour [43]. HDL-C correlated negatively with feelings of past failures or suicidal thoughts. Nevertheless, we did not find associations between TC and symptoms of depression what was shown by other authors [44]. Maes et al. [45] suggested that major depression was accompanied by reduced formation of cholesterol esters and perhaps by impairment of reverse cholesterol transport. The latter is accompanied by lower serum HDL-C. Serum HDL-C was significantly lower in depressed men who had made suicidal attempts than in those without such suicidal behaviour. Maimanee and Al-Hazimi [46] suggested that the youth with low level of TC was more exposed to acute depression than the elders. It is known that brain membranes have a very high content of polyunsaturated fatty acids (PUFAs): omega 3 and 6. These two classes of fatty acids cannot be synthesised by the organism and have to be taken from alimentation. Phospholipids composed of PUFAs chains increase the membrane fluidity which is also determined by the phospholipids/free cholesterol ratio, as cholesterol increases membrane viscosity. Any dietary lack of essential PUFAs has consequences on cerebral development $[44,47]$. It has been suggested that the increased prevalence of depression in the European countries in the $20^{\text {th }}$ century could be related to changes in alimentary patterns, in which consumption of omega 3 PUFAs constantly diminished [48]. These findings have challenged the public health programs aimed at promoting the decrease of cholesterol, and even suggested to suspend the administration of lipid lowering drugs [44].

\section{CONCLUSIONS}

Only low blood lipids may have influence on emotional well-being in young healthy men. The decreased testosterone level becomes probably the main risk factor for the lower mood in middle-aged men. Atherosclerosis risk factors and general health worsen with the advancing age, but they have no significant effect on psychological situation.

\section{ACKNOWLEDGEMENTS}

This work was supported by Grants No. 508-02-054 and 503-1089-2/3 from the Medical University of Lodz, Poland.

\section{REFERENCES}

[1] Bancroft, J. (1995) The menstrual cycle and the well being of women. Social Science \& Medicine, 41(6), 785791.

[2] Chrisler, J.C. and Caplan, P. (2002) The strange case of Dr. Jekyll and Ms.Hyde: How PMS became a cultural phenomenon and a psychiatric disorder. Annual Review of Sex Research, 13, 274-306.

[3] Frey, B.N., Lord, C. and Soares, C.N. (2008) Depression during menopausal transition: A review of treatment 
strategies and pathophysiological correlates. Menopause International, 14(3) 123-128.

[4] Zarrouf, F.A., Artz, S., Griffith, J., Sirbu, C. and Kommor, M. (2009) Testosterone and depression: Systematic review and meta-analysis. Journal of Psychiatric Practice, 15(4), 289-305.

[5] Joshi, D., van Schoor, N.M., de Ronde, W., Schaap, L.A., Comijs, H.C., Beekman, A.T. and Lips, P. (2009) Low free testosterone levels are associated with prevalence and incidence of depressive symptoms in older men. Clinical Endocrinology (Oxford) [ahead of print].

[6] Nieschlag, E., Swerdloff, R., Behre, H.M., Gooren, L.J., Kaufman, J.M., Legros, J.J., Lunenfeld, B., Morley, J.E., Schulman, C., Wang, C., Weidner, W. and Wu, F.C. (2006) Investigation, treatment, and monitoring of late-onset hypogonadism in male: ISA, ISSAM, and EAU recommendations. Journal of Andrology, 27(2), 135-137.

[7] Morales, A., Buvat, J., Gooren, L.J., Guay, A.T., Kaufman, J.M., Tan, H.M. and Torres, L.O. (2004) Endocrine aspects of sexual dysfunction in men. Journal of Sexual Medicine, 1(1), 69-81.

[8] Nease, D.E. and Malouin, J.M. (2003) Depression screening: A practical strategy. Journal of Family Practice, 52(2), 118-124.

[9] Burris, A.S., Banks, S.M., Carter, C.S., Davidson, J.M. and Sherins, R.J. (1992) A long-term prospective study of the physiologic and behavioral effects of hormone replacement in untreated hypogonadal men. Journal of Andrology, 13(4), 297-304.

[10] Morley, J.E., Perry, H.M. 3rd, Kaiser, F.E., Kraenzle, D., Jensen, J., Houston, K., Mattammal, M. and Perry, H.M. Jr. (1993) Effect of testosterone replacement therapy in older hypogonadal males: A retrospective study. Journal of the American Geriatric Society, 41(2), 149-152.

[11] Wang, C., Cunningham, G., Dobs, A., Iranmanesh, A., Matsumoto, A.M., Snyder, P., Weber, T., Berman, N., Hull, L. and Swerdloff, R.S. (2004) Long-term testosterone gel (Androgel) treatment maintains beneficial effects on sexual function and mood, lean and fat mass, and bone mineral density in hypogonadal men. Journal of Clinical Endocrinology \& Metabolism, 89(5), 20852098.

[12] Libe, R., Barbetta, L., Dall'Asta, C., Salvaggio, F., Gala, C., Beck-Pecoz, P. and Ambrosi, B. (2004) Effects of dehydroepiandrosterone (DHEA) supplementation on hormonal, metabolic and behavioral status in patients with hypoadrenalism. Journal of Endocrinological Investigation, 27(8), 736-741

[13] Von Muhlen, D., Laughlin, G.A., Kritz-Silverstein, D. and Barrett-Connor, E. (2007) The dehydroepiandrosterone and wellness (DAWN) study: Research design and methods. Contemporary Clinical Trials, 28(2), 153-168.

[14] Sachar, E.J., Halpern, F., Rosenfeld, R.S., Gallagher, T.F. and Hellman, L. (1973) Plasma and urinary testosterone levels in depressed men. Archives of General Psychiatry, 28(1), 15-18.

[15] Rubin, R.T., Poland, R.E. and Lesser, I.M. (1989) Neuroendocrine aspects of primary endogenous depression VIII. Pituitary-gonadal axis activity in male patients and matched control subjects. Psychoneuroendocrinology, 14(3), 217-229.

[16] Jones, B.N. and Reifler, B.V. (1994) Depression co-existing with dementia: Evaluation and treatment Medical Clinics of North America, 78(4), 823-840.

[17] Thomas, A.J., Kalaria, R.N. and O'Brien, J.T. (2004) Depression and vascular disease: What is the relationship? Journal of Affective Disorders, 79(1), 81-95.

[18] Shin, J.Y., Suls, J. and Martin, R. (2008) Are cholesterol and depression inversely related? A meta-analysis of the association between two cardiac risk factors. Annals of Behavioral Medicine, 36(1), 33-43.

[19] Lehto, S.M., Hintikka, J., Niskanen, L., Tolmunen, T., Koivumaa-Honkanen, H., Honkalampi, K. and Vijnamaki, H. (2008) Low HDL cholesterol associates with major depression in a sample with a 7-year history of depressive symptoms. Progress in Neuro-Psychopharmacology and Biological Psychiatry, 32(6), 1557-1561.

[20] Sutton, P.W., Love, J.G., Bell, J., Christie, E., Mayrhofer, A., Millman, Y., Williams, H. and Yuill, C. (2005) The emotional well-being in young people: A review of the literature. School of Applied Social Studies, Robert Gordon University, Aberdeen, Scotland.

[21] Beck, A.T., Steer, R.A. and Brown, G.K. (1996) Manual for the Beck Depression Inventory-II. Psychological Corporation, San Antonio, TX, USA.

[22] Kaufman, J.M. and Vermeulen, A. (2005) The decline of androgen levels in elderly men and its clinical and therapeutic implications. Endocrine Review, 26(6), 833-876.

[23] Liu, P.Y., Beilin, J., Meier, C., Nguyen, T.V., Center, J.R., Leedman, P.J., Seibel, M.J., Eisman, J.A. and Handelsman, D.J. (2007) Age-related changes in serum testosterone and sex hormone binding globulin in Australian Men: longitudinal analyses of two geographically separate regional cohorts. Journal of Clinical Endocrinology \& Metabolism, 92(9), 3599-3603.

[24] Wu, F.C., Tajar, A., Pye, S.R., Silman, A.J., Finn, J.D., O’Neil, T.W., Bartfai, G., Casanueva, F., Forti, G., Giwercman, A., Huhtaniemi, I.T., Kula, K., Punab, M., Boonen, S., Vanderschurren, D. and the EMAS study group (2008) Hypothalamic-pituitary-testicular axis disruptions in older men are differentially linked to age and modifiable risk factors: The male aging study. Journal of Clinical Endocrinology \& Metabolism, 93, 2737-274.

[25] Swerdloff, R.S. and Wang, C. (2002) Androgens and the aging male. In: Lunenfeld, B. and Gooren, L., Eds., Textbook of men's health. The Parthenon Publishing Group, 148-157.

[26] Nafziger, A.N., Bowlin, S.J., Jenkins, P.L. and Pearson, T.A. (1998) Longitudinal changes in dehydroepiandrosterone concentrations in men and women. Journal of Laboratory \& Clinical Medicine, 131(4), 316-323.

[27] Feldman, H.A., Longcope, C., Derby, C., Johannes, C.B., Araujo, A.B., Coviello, A.D., Bremner, W.J. and McKinlay, J.B. (2002) Age trends in the level of serum testosterone and other hormones in middle-aged men: Longitudinal results from the Massachusetts Male Aging Study. Journal of Clinical Endocrinology \& Metabolism, 87(2), 589-598.

[28] Ferrini, R.L. and Barrett-Connor, E. (1998) Sex hormones and age: A cross-sectional study of testosterone and estradiol and their bioavailable fractions in community-dwelling men. American Journal of Epidemiology, 147(8), 750-754.

[29] Barrett-Connor, E. (1990) A prospective, population- 
based study of androstendione, estrogens and prostate cancer. Cancer Research, 50, 169-173.

[30] Barrett-Connor, E., Von Mühlen, D.G. and KritzSilverstein, D. (1999) Bioavailable testosterone and depressed mood in older men: The Rancho Bernardo Study. Journal of Clinical Endocrinology \& Metabolism, 84(2), 573-577.

[31] Araujo, A.B., Durante, R., Feldman, H.A., Goldstein, I. and McKinlay, J.B. (1998) The relationship between depressive symptoms and male erectile dysfunction: Crosssectional results from the Massachusetts Male Aging Study. Psychosomatic Medicine, 60(4), 458-465.

[32] Seidman, S.N. and Walsh, B.T. (1999) Testosterone and depression in aging male. American Journal of Geriatric Psychiatry, 7(1), 18-33.

[33] Carnahan, R.M. and Perry, P.J. (2004) Depression in aging men: The role of testosterone. Drugs \& Aging, 21(6), 361-376.

[34] Woodman, C.L. and Williams, W.R. (1996) Testosterone, mood, and psychotropic medication. American Psychiatric Association, New York.

[35] Travison, T.G., Morley, J.E., Araujo, A.B., O’Donnell, A.B. and McKinlay, J.B. (2006) The relationship between libido and testosterone levels in aging men. Journal of Clinical Endocrinology \& Metabolism, 91(7), 2509-2513.

[36] O'Connor, D.B., Corona, G., Forti, G., Tajar, A., Lee, D.M., Finn, J.D., Bartfai, G., Boonen, S., Casanueva, F.F., Giwercman, A., Huhtaniemi, I.T., Kula, K., O'Neill, T.W., Pendleton, N., Punab, M., Silman, A.J., Vanderschueren, D., Wu, F.C.W. and the European Male Ageing Study group (2008) Assessment of sexual health in aging men in Europe: Development and validation of the European Male Ageing Study sexual function questionnaire. Journal of Sexual Medicine, 5(6), 1374-1385.

[37] Morley, J.E., Charlton, E., Patrick, P., Kaiser, F.E., Cadeau, P., McCready, D. and Perry, H.M. 3rd (2000) Validation of a screening questionnaire for androgen deficiency in aging males. Metabolism, 49(9), 1239-1242.

[38] Vermeulen, A., Goemaere, S. and Kaufman, J.M. (1999) Sex hormones, body composition and aging. Aging Male, 2(1), 8-15.

[39] Isidori, A.M., Giannetta, E., Gianfrilli, D., Bonofacio, V.,
Aversa, A., Isidori, A., Fabbri, A. and Lenzi, A. (2005) Effects of testosterone on body composition, bone metabolism and serum lipid profile in middle-aged men: A meta-analysis. Clinical Endocrinology (Oxford), 63(4), 381- 394.

[40] Slowikowska-Hilczer, J., Marchlewska, K., WalczakJedrzejowska, R., Oszukowska, E., Guminska, A., Kramek, E., Jastrzebska, S., Zawadzka, E., Kula, W., Habib, M., Trzuskowska, D., Jakubowski, L. and Kula, K. (2007) High risk of atherosclerosis in men aged 20-39 from Lodz agglomeration. Polski Merkuriusz Lekarski, 23(138), 417-425.

[41] Marin, P. (2002) Testosterone, aging and body composition. In: Lunenfeld, B. and Gooren, L., Eds., Textbook of men's health. The Parthenon Publishing Group, 227-234.

[42] Wu, F.C.W. and Von Eckardstein, A. (2003) Androgens and coronary artery disease. Endocrine Review, 24(2), 183-217.

[43] Rabe-Jablonska, J. and Poprawska, I. (2000) Levels of serum total cholesterol and LDL-cholesterol in patients with major depression in acute period and remission. Medical Science Monitor, 6(3), 539-547.

[44] Colin, A., Reggers, J., Castronovo, V. and Ansseau, M. (2003) Lipids, depression and suicide. Encephale, 29(1), 49-58.

[45] Maes, M., Smith, R., Christophe, A., Vadoolaeghe, E., Van Gastel, A., Neels, H., Demedts, P., Wauters, A. and Meltzer, H.Y. (1997) Lower serum high-density lipoprotein cholesterol (HDL-C) in major depression and in depressed men with serious suicidal attempts: Relationship with immune-inflammatory markers. Acta Psychiatrica Scandinavica, 95(3), 212-221.

[46] Maimanee, T.A. and Al-Hazmi, S. (2009) Relationship between blood cholesterol level and acute depression. Journal of the Egyptian Society of Parasitology, 39(2), 653-663.

[47] Owen, C., Rees, A.M. and Parker, G. (2008) The role of fatty acids in the development and treatment of mood disorders. Current Opinion in Psychiatry, 21(1), 19-24.

[48] Young, G. and Conquer, J. (2005) Omega-3 fatty acids and neuropsychiatric disorders. Reproduction Nutrition Development, 45(1), 1-28. 